\title{
A retrospective study: Does upper airway morphology differ between non-positional and positional obstructive sleep apnea?
}

\author{
Xiao Jiao ${ }^{1,2}$ ， Jianyin Zou ${ }^{1,2}$ ， Suru Liu ${ }^{1,2}$ ， Jian Guan ${ }^{1,2}$ ， Hongliang Yi Corresp., 1,2 , Shankai Yin ${ }^{1,2}$ \\ ${ }^{1}$ Otolaryngology, Shanghai Jiaotong University Affiliated Sixth People's Hospital, Shanghai, CHN \\ 2 Otolaryngology Institute of Shanghai Jiao Tong University, Shanghai, CHN \\ Corresponding Author: Hongliang Yi \\ Email address: yihongl@126.com
}

Objective: To explore the differences in upper airway morphology between positional (POSA) and non-positional (NPOSA) obstructive sleep apnea. Methods: This retrospective study enrolled 75 patients (45 NPOSA and 30 POSA) who underwent polysomnography (PSG) and computed tomography (CT). The differences in, and relationships of, the PSG values and CT data between POSA and NPOSA were analyzed. Results: Significant $(p<0.05)$ differences between the two groups were found in the apnea/hypopnea index $(\mathrm{AHI})$, lateral-AHI (L-AHI), soft palate length (SPL), cross-sectional palatopharyngeal area, and the coronal diameter $(C D)$ of the palatopharyngeal area at the narrowest part of the glossopharynx, which were all higher in POSA, except for SPL, AHI, and L-AHI. L-AHI was correlated with the cross-sectional area $(r=-0.306, p=0.008)$ and $C D(r=-0.398, p<0.001)$ of the palatopharyngeal area, the cross-sectional area $(r=-0.241, p=0.038)$ and $C D$ $(r=-0.297, p=0.010)$ of the narrowest level of the glossopharynx, the $C D$ of the glossopharynx $(r=-0.284, p=0.013)$, body mass index (BMI, $r=0.273, p=0.018)$, SPL $(r=0.284, p=0.014)$, and vallecula-tip of tongue $(r=0.250, p=0.030)$. The SPL and CD at the narrowest part of the glossopharynx were included in the simplified screening model. Conclusions: In NPOSA, the CD of the upper airway was smaller, and the soft palate was longer, than in POSA. These differences may play significant roles in explaining the main differences between NPOSA and POSA. 
1 A retrospective study: Does upper airway morphology differ between non-positional and positional obstructive sleep apnea?

3 The manuscript type: Original contribution

4 Xiao Jiao ${ }^{1,2}$ Jianyin Zou ${ }^{1,2}$ Suru Liu ${ }^{1,2}$ Jian Guan $^{1,2}$ Hongliang Yi ${ }^{1,2 *}$ Shankai Yin ${ }^{1,2}$

6 'Otolaryngology, Shanghai Jiaotong University Affiliated Sixth People's Hospital, Shanghai,

$7 \mathrm{CHN}$

8 2Otolaryngology Institute of Shanghai Jiao Tong University, Shanghai, CHN

9

$10{ }^{*}$ Corresponding to: Hongliang Yi, E-mail: yihongl@126.com.

11

12

13

14

15

16

17

18

19

20 


\section{Abstract}

24 Objective: To explore the differences in upper airway morphology between positional (POSA)

25 and non-positional (NPOSA) obstructive sleep apnea.

26 Methods: This retrospective study enrolled 75 patients (45 NPOSA and 30 POSA) who

27 underwent polysomnography (PSG) and computed tomography (CT). The differences in, and

28 relationships of, the PSG values and CT data between POSA and NPOSA were analyzed.

29 Results: Significant $(p<0.05)$ differences between the two groups were found in the

30 apnea/hypopnea index (AHI), lateral-AHI (L-AHI), soft palate length (SPL), cross-sectional

31 palatopharyngeal area, and the coronal diameter $(C D)$ of the palatopharyngeal area at the

32 narrowest part of the glossopharynx, which were all higher in POSA, except for SPL, AHI, and

33 L-AHI. L-AHI was correlated with the cross-sectional area $(\mathrm{r}=-0.306, p=0.008)$ and $\mathrm{CD}(\mathrm{r}=$

$340.398, p<0.001)$ of the palatopharyngeal area, the cross-sectional area $(\mathrm{r}=-0.241, p=0.038)$ and

$35 \mathrm{CD}(\mathrm{r}=-0.297, p=0.010)$ of the narrowest level of the glossopharynx, the CD of the

36 glossopharynx $(\mathrm{r}=0.284, p=0.013)$, body mass index (BMI, $\mathrm{r}=0.273, p=0.018), \mathrm{SPL}(\mathrm{r}=0.284$,

$37 p=0.014)$, and vallecula-tip of tongue $(\mathrm{r}=0.250, p=0.030)$. The SPL and CD at the narrowest part

38 of the glossopharynx were included in the simplified screening model. 
39 Conclusions: In NPOSA, the CD of the upper airway was smaller, and the soft palate was longer,

40 than in POSA. These differences may play significant roles in explaining the main differences

41 between NPOSA and POSA.

\section{Introduction}

45 Obstructive sleep apnea-hypopnea syndrome (OSAHS) is harmful to health. Its major clinical

46 features include snoring, apnea, and daytime hypersomnolence; it is also correlated with diabetes,

47 ischemic heart disease, chronic cor pulmonale, and cerebrovascular disease. Based on differences

48 in the apnea/hypopnea index (AHI) in different positions, OSAHS is divided into positional

49 obstructive sleep apnea (POSA) and non-positional obstructive apnea (NPOSA). POSA is

50 defined as having an AHI in the supine sleeping position that is at least twice the value in other

51 positions (Oksenberg, et al. 2012); otherwise, the condition is considered to be NPOSA. NPOSA

52 patients are prone to having more severe OSAHS than POSA patients (Oksenberg et al. 1997;

53 Oksenberg et al. 2012). Additionally, a variety of treatment methods are available for OSAHS,

54 but the effects of the these treatments on NPOSA and POSA vary (de Vries et al. 2015; Lee et al.

55 2012; Levendowski et al. 2014)). However, the exact mechanisms underlying NPOSA and

56 POSA are unclear; anthropometric characteristics, upper airway morphology, and anatomical

57 structures may all play roles. Many studies have focused on the differences between NPOSA and 
POSA, such as age and body mass index (BMI) (Oksenberg, et al. 1997; Oksenberg A, et al. 2012). There are differences in the contributions made by age and BMI to POSA (Oksenberg et al. 1997; Teerapraipruk et al. 2012). Only a few studies have compared the palatopharyngeal morphology (Soga et al. 2009), craniofacial structures and soft tissues of the lateral pharyngeal wall (Saigusa et al. 2009) between POSA and NPOSA in Caucasians. Differences in the upper airway morphology at other levels, and differences in the soft tissues of the upper airway (such as the length and thickness of the soft palate) between NPOSA and POSA are not known. Currently, the impact of these factors on the substantial differences evident between NPOSA and POSA is uncertain; there are especially few studies on Chinese populations. Therefore, to enhance our understanding of the pathogenesis of NPOSA and POSA, this study explored differences in the upper airway morphology and anatomical structures between two groups of Chinese patients using computed tomography (CT) and polysomnography (PSG).

\section{Materials \& Methods}

72 This project was approved by the Ethics Committee of our hospital and complied with all relevant tenets of the Declaration of Helsinki (2016-31-(1)). All participants provided written informed consent before inclusion in the study.

\section{Subjects}

The study initially recruited 105 consecutive adult patients with OSAHS who underwent surgery because they refused CPAP in our hospital from January 2005 to December 2014 (BMI $<35$

$\mathrm{kg} / \mathrm{m}^{2}$ ). Patients with chronic airway diseases, obstructive pulmonary disease, and systemic 
79 diseases were excluded. Eleven subjects were excluded because they refused to undergo CT

80 testing or because the orbitale-porion plane (i.e., the Frankfort horizontal plane) was not parallel

81 to the ground plane on CT of the head (Yu XJ, Fujimoto K \& Urushibata K. 2003). All patients

82 were asked to complete the Epworth Sleepiness Scale and a sleep questionnaire, and to undergo

83 overnight PSG. The study excluded 17 patients who slept for less than $30 \mathrm{~min}$ in the lateral or

84 supine position (Oksenberg et al., 1997), and 2 patients whose central or mixed sleep-disordered

85 breathing events accounted for more than $25 \%$ of all sleep-breathing episodes (Strollo et al.,

86 2014). Ultimately, the study included 75 patients (Fig. 1).

87 2. Methods

88 The head and neck multislice CT, overnight PSG test, and physical parameters were

89 retrospectively reviewed in all subjects.

$90 \quad 2.1$ Body parameters

91 BMI was calculated by dividing the patient's weight in kilograms by height squared in meters

92 squared. The tongue position and tonsil size were assessed using the Friedman staging system

93 before overnight PSG.

94 2.2 PSG test

95 All subjects underwent overnight PSG (Alice 4; Respironics, Pittsburgh, PA, USA), which not

96 only identified sleep-disordered breathing events but also included a position sensor that could

97 differentiate the sleep position as supine $(\mathrm{S})$, left side $(\mathrm{L})$, right side, and prone. The AHI is

98 classified into three types depending on the sleep position: the overall AHI, AHI in the supine

99 position ( $\mathrm{S}-\mathrm{AHI})$, and $\mathrm{AHI}$ in the lateral position ( $\mathrm{L}-\mathrm{AHI})$. The monitoring time was $>7 \mathrm{~h}$. The 
100 records were analyzed by professionals the next morning. Patients with OSHA who had AHI

101 values in the supine sleeping position at least two-fold greater than the values in other positions

102 were defined as having POSA; the other OSHA patients were defined as having NPOSA

103 (Oksenbergl. 2012). No subjects consumed strong tea, coffee, or drugs that would have had

104 calming effects or caused sleep before the PSG test.

1052.3 CT analysis

106 CT (peak voltage, $120 \mathrm{kV}$; tube current, $130 \mathrm{~mA}$; pitch, 0.75; section thickness, $2 \mathrm{~mm}$; and tube

107 current-time product, $100 \mathrm{~mA}$ ) was performed on all patients in the supine position, from the

108 skull base to the hyoid bone, with the head positioned correctly (the orbitale-porion plane

109 parallel to the ground plane), the upper and lower teeth naturally together, the tongue tip against

110 the premaxillary teeth, and with all patients breathing quietly without swallowing or chewing.

111 Philips DICOM viewer software was used to measure CT parameters including the angles, cross-

112 sectional areas, and soft tissue parameters of the upper airway: the sella (S), nasion (N),

113 subspinale (A), supremental (B), basion (Ba), vallecula (V), tip of tongue (T), anterior nasal

114 spine (ANS), posterior nasal spine (PNS), angles relative to each other (e.g., SNA, SNB, BaSN,

115 and ANB), and the posterior airway space (Fig. 2). Then, the sagittal (SD) and coronal (CD)

116 diameters and cross-sectional area were measured at the palatopharynx, glossopharynx ,

117 hypopharynx, and the narrowest part of the glossopharynx (Sakatet al. 2016) (Fig. 3). In addition,

118 the soft tissues of the upper airway were measured, including the vallecula-tip of tongue (VT, the

119 tongue length), soft palate length, and soft palate thickness (SPT).

120 3. Statistical analysis 
121 The statistical program SPSS 20.0 (IBM, Armonk, NY, USA) was used to compare the data

122 associated with anthropometric characteristics, upper airway morphology, and PSG between the

123 POSA and NPOSA groups. Normally distributed data were compared using the independent

124 samples $t$-test and are presented as the mean \pm standard deviation. Non-normally distributed data

125 were analyzed using the Mann-Whitney test and are presented as the median (interquartile range).

126 Correlations between variables were examined using Spearman's correlation or the Pearson test.

127 Forward logistic regression analysis was performed to select the main correlative parameters of

128 POSA. The accuracy of the diagnostic model was examined using the receiver operating

129 characteristics (ROC) curve. A value of $p<0.05$ was used to indicate statistical significance.

\section{Results}

132 The 75 subjects were divided into NPOSA $(n=40)$ and POSA $(n=35)$ groups. The mean age of

133 the subjects was $39.2 \pm 9.4$ years, while the mean age of the NPOSA and POSA groups was 40.8

$134 \pm 5.3$ and $38.6 \pm 11.2$ years $(p=0.043)$. The mean BMI was $27.4 \pm 3.2 \mathrm{~kg} / \mathrm{m}^{2}$. There was a

135 significant $(p<0.01)$ difference in the AHI between NPOSA and POSA $(60.1 \pm 19.4 v s .42 .5 \pm$

13618.5 event/h), and the L-AHI of POSA was significantly $(p<0.001)$ lower than that of NPOSA.

137 However, no significant difference between the two groups was found for BMI, tongue position,

138 tonsil size, Friedman staging, or S-AHI $(p>0.05)$ (Table 1).

139 The SPL was significantly $(p=0.005)$ longer in NPOSA $(36.1 \pm 5.0 \mathrm{~mm})$ than in POSA $(33.0 \pm$

$1403.9 \mathrm{~mm})$. The cross-sectional area of the palatopharynx was significantly $(p=0.027)$ smaller in

141 the NPOSA group [67.4 (31.1) vs. $80.3(43.0) \mathrm{mm}^{2}$ ]. In addition, the CD of the palatopharynx 
142 and the narrowest part of the glossopharynx were significantly $(p<0.05)$ smaller in NPOSA than

143 in POSA. However, there were no statistical differences in SNA, SNB, ANB, BaSN, ANS, PNS,

144 SPT, VT, or the SD to CD ratios of the glossopharynx and hypopharynx (all $p>0.05$ ) between the

145 two groups. Although, no significant difference group was found in CD or the cross-sectional

146 area of the glossopharynx or hypopharynx, the values were smaller in NPOSA than POSA

147 (Table 2).

148 After adjusting for age as a confounding factor, the AHI, SPL, and SD to CD ratios of the

149 glossopharynx and L-AHI were significantly $(p<0.05)$ larger in NPOSA than POSA, and the CD

150 of the glossopharynx was significantly smaller. However, no significant difference was found in

$151 \mathrm{CD}$ or the cross-sectional area of the palatopharynx between the two groups.

152 As assessed using Pearson and Spearman correlation analyses, L-AHI was correlated with the

153 cross-sectional area $(\mathrm{r}=0.306, p=0.008)$ and $\mathrm{CD}(\mathrm{r}=0.398, p<0.001)$ of the palatopharynx, the

154 cross-sectional area $(\mathrm{r}=0.241, p=0.038)$ and $\mathrm{CD}(\mathrm{r}=0.297, p=0.010)$ of the narrowest part of

155 the glossopharynx, the $\mathrm{CD}$ of the glossopharynx $(\mathrm{r}=0.284, p=0.013)$, BMI $(\mathrm{r}=0.273, p=0.018)$,

$156 \operatorname{SPL}(\mathrm{r}=0.284, p=0.014)$, and VT $(\mathrm{r}=0.250, p=0.030)$ in all subjects.

157 Forward logistic regression analysis of the relative influence of these independent variables on

158 NPOSA, the soft palate length, the CD of the narrowest part of the glossopharynx, and age were

159 included in the regression model (Supplementary Table 1). The cut-off point for soft palate

160 length was $35.4 \mathrm{~mm}$.

161

162 Discussion 
163 The AHI is significantly higher in NPOSA than POSA (Oksenberg et al. 1997), consistent with

164 our results. Aging is known to be a major contributor to the risk of OSAHS; its prevalence and

165 severity increase with age and may be associated with factors such as a reduction in muscle tone,

166 a reduced airway lumen, and changes in lung volume and ventilatory control stability ((Edwards

167 et al. 2010; Kim et al. 2015). In the present study, the NPOSA patients were older than the POSA

168 patients. Although there was no correlation between age and AHI or L-AHI, the difference in

169 upper airway parameters between the two groups changed after adjusting for age. Age was

170 included in the regression model as one of the independent risk factors for NPOSA. This may be

171 because the activity of the pharyngeal dilator muscles in response to negative pharyngeal

172 pressure is impaired upon aging, increasing the compliance of the pharyngeal wall in both the

173 supine and lateral positions. Furthermore, age may affect upper airway collapse in different

174 planes and play a role in the susceptibility to NPOSA.

175 Cephalometry is used to screen for anatomical abnormalities in OSAHS patients. Various studies

176 have shown that the pharyngeal dimensions are correlated with both craniofacial skeletal

177 morphology (Bacon et al. 1988; Wang et al. 2014; Yu XJ,;Fujimoto K, Urushibata K 2003) and

178 airway obstruction in OSAHS patients (Ardehali et al. 2016), including those with ANB (Ceylan

179 \& Oktay, 1995), SNB (Ardehali et al. 2016), and ANS-PNS (Yu XJ, Fujimoto K \& Urushibata K.

180 2003). It is well-known that significant differences are apparent between NPOSA and POSA in

181 terms of clinical symptoms, and, theoretically, the characteristics of the craniofacial skeleton

182 may play a role in this context. However, we found no significant difference in craniofacial 
183 morphology (apart from soft palate length) between NPOSA and POSA, suggesting that skeletal

184 morphology did not play a significant role in NPOSA.

185 We found that the L-AHI was associated with soft palate length; specifically, the more the length

186 of the soft palate exceeded $>35.4 \mathrm{~mm}$ the greater the risk of NPOSA. This may be explained in

187 several ways. Historically, the soft palate was larger in OSAHS than non-OSAHS patients (Lowe

188 et al. 1996), and has been shown to play a key role in OSAHS (Bacon et al. 1990). In addition,

189 fatty infiltration (regardless of obesity status) (Zohar et al. 1998) impairs soft palate sensation,

190 which correlates with the severity of snoring (Jeong et al. 2016); the soft palate becomes altered

191 and exhibits a fiber-type appearance caused by the additional load on the velopharyngeal

192 muscles (Lindman \& Stål 2002) in OSAHS patients. These factors may affect compliance of the

193 soft palate and can cause narrowing of the upper airway. Also, inflammatory processes increase

194 the thickness of the soft palate (Berger et al. 2002), which also tends to be thicker in the supine

195 position in OSAHS patients because gravitational force reduces the SD of the upper airway

196 (Lowe et al. 1996). In comparison, in the lateral position, the gravitational force acting on the

197 longer soft palate of NPOSA patients should decrease the CD of the upper airway. Furthermore,

198 our simplified PRE screening model included soft palate length as an independent predictor of

199 NPOSA. Our results suggest that soft palate length plays a significant role in the direction of

200 upper airway collapse during sleep, although the reason for the increased susceptibility to

201 NPOSA in those with longer soft palates remains unclear. Our work suggests that NPOSA not

202 only involves anteroposterior collapse, but also transverse collapse in the plane of the

203 palatopharynx, whereas POSA involves only the former. 
204 In OSAHS patients, single or multiple planes of upper airway collapse, such as the

205 palatopharyngeal, glossopharyngeal, and hypopharyngeal planes (Tang et al. 2012; Torre et al.

206 2016; Vroegop et al. 2014), and the complete concentric collapse of the glossopharynx, are

207 correlated significantly with the severity of OSAHS (Ravesloot \& de Vries 2011; Schwartz et al.

208 2015; Vroegop et al. 2014). In our study, the negative correlations between L-AHI and the CD of

209 the palatopharynx and glossopharynx demonstrated that the lateral diameter of the upper airway

210 was highly predictive of the value of AHI (Tsai et al. 2003). Second, after adjusting for age,

211 patients with NPOSA tended to have more severe OSAHS, with a smaller CD at the narrowest

212 level of the glossopharynx and a higher L-AHI. Third, the CD of the narrowest level of the

213 glossopharynx, age, and SPL were included in the regression model. These results indicate that

214 the smaller lateral distance in NPOSA patients (Pevernagie et al. 1995; Soga et al. 2009),

215 particularly at the level of the glossopharynx, plays an essential role in the differences between

216 NPOSA and POSA. There was no significant difference in the SD of the upper airway or S-AHI

217 between the two groups, suggesting that the pathogenesis of NPOSA in the supine position might

218 be similar to that of POSA. Additionally, in NPOSA, a round airway was seen in the

219 palatopharynx and an elliptical airway, with the SD as the long axis, was seen at the narrowest

220 level of the glossopharynx. In the supine position in POSA, an elliptical airway with the CD as

221 the long axis was seen in the palatopharynx ((Ciscar et al. 2001; Walsh et al. 2008). Perhaps the

222 different airway shapes between NPOSA and POSA, caused by the fat distribution in the lateral

223 pharyngeal wall and the reduction in muscle tone (Saigusa et al. 2009), led to differences in the

224 direction of upper airway collapse and impaired breathing in sleep (Foster et al. 2009). Hence, 
225 the upper airway morphology characteristics of the two groups may play a significant role in the

226 substantial differences between NPOSA and POSA.

227 Our small sample size and the lack of a control group are limitations of our study. Also, the

228 patients were very young and the results might thus not be generalizable. Moreover, we did not

229 collect nocturnal rostral fluid shift or electroencephalographic data, and may also have ignored

230 other factors that could affect our results. Such limitations are disadvantages common to many

231 retrospective studies. Another limiting factor is that CT was performed with all patients awake

232 and the data may thus not accurately reflect the dynamics of upper airway collapsibility during

233 sleep. Thus, future studies with larger sample numbers are warranted to further examine and

234 prospectively elucidate the mechanisms underlying NPOSA and POSA.

235 This study identified characteristic differences in the upper airway between NPOSA and POSA,

236 which may partly explain the differences in clinical characteristics and treatment success rates

237 between the two groups. The prognosis of OSAHS may be improved by choosing the appropriate

238 treatment according to the upper airway morphology characteristics. POSA patients may gain

239 more benefit from positional therapy (de Vries et al. 2015; Levendowski et al. 2014)),

240 mandibular advancement devices, (Lee et al. 2012) and uvulopalatopharyngoplasty (Li et al.

241 2013), whereas NPOSA patients will probably almost always require continuous positive airway

242 pressure therapy and/or more complex treatment.

244 Conclusion

245 In terms of upper airway morphology, the NPOSA group had a smaller pharyngeal CD and a 
246

247

248

249

250

251

252

253

254

255

256

257

258

259

260

261

262

263

264

265

266

267

268

269

270

271

272

273

274

275

276

277

278

longer soft palate than the POSA group. In addition to the AHI, the main differences between

NPOSA and POSA patients were in the soft palate length and the CD at the narrowest part of the glossopharynx.

Acknowledgments: The authors would like to thank all subjects who participated in the study.

\section{References}

Ardehali MM, Zarch VV, Joibari ME, and Kouhi A. 2016. Cephalometric Assessment of Upper Airway Effects on Craniofacial Morphology. J Craniofac Surg 27:361-364.

Bacon WH, Krieger J, Turlot JC, Turlot Jc ,Stierle JL, and Stierle JL. 1988. Craniofacial characteristics in patients with obstructive sleep apneas syndrome. Cleft Palate J 25:374378.

Bacon WH, Turlot Jc ,Krieger J, Krieger J ,Stierle JL, and Stierle JL. 1990. Cephalometric evaluation of pharyngeal obstructive factors in patients with sleep. Angle Orthod 60:115122.

Berger G, Gilbey P, Hammel I, Hammel I, Ophir D, and Ophir D. 2002. Histopathology of the uvula and the soft palate in patients with mild, moderate. Laryngoscope 112:357-363.

Ceylan I, and Oktay H. 1995. A study on the pharyngeal size in different skeletal patterns. Am J Orthod Dentofacial Orthop 108:69-75.

Ciscar MA, Juan G, Martinez V, Martinez V, Ramon M, Ramon M, Lloret T, Lloret T , Minguez $\mathrm{J}$, Minguez J, Armengot M, Armengot M, Marin J, Marin J, Basterra J, and Basterra J. 2001. Magnetic resonance imaging of the pharynx in OSA patients and healthy subjects. Eur Respir J 17:79-86.

de Vries GE, Hoekema A, Doff MH, Kerstjens HA, Meijer PM, van der Hoeven JH, and Wijkstra PJ. 2015. Usage of positional therapy in adults with obstructive sleep apnea. J Clin Sleep Med 11:131-137.

Edwards BA, O'Driscoll DM, Ali A, Jordan AS, Trinder J, and Malhotra A. 2010. Aging and sleep: physiology and pathophysiology. Semin Respir Crit Care Med 31:618-633.

Foster GD, Borradaile KE, Sanders MH, Millman R, Zammit G, Newman AB, Wadden TA, Kelley D, Wing RR, Pi-Sunyer FX, Reboussin D, Kuna ST; Sleep AHEAD Research Group of Look AHEAD Research Group. 2009. A randomized study on the effect of weight loss on obstructive sleep apnea among obese patients with type 2 diabetes: the 
279

280

281

282

283

284

285

286

287

288

289

290

291

292

293

294

295

296

297

298

299

300

301

302

303

304

305

306

307

308

309

310

311

312

313

314

315

316

317

318

319

Sleep AHEAD study. Arch Intern Med 169:1619-1626 LID 1610.1001/archinternmed.2009.1266 [doi].

Jeong KH, Yang Y, Choi HR, Cho JH, Kim GT, and Kim JK. 2016. Assessment of the Change in Palatal Sensation in Obstructive Sleep Apnea Patients by Using Two-Point Palatal Discrimination. Clin Exp Otorhinolaryngol:1-7.

Kim SW, Kim BY, Han JJ, Hwang JH, Jung K, Kim M, and Kim SW. 2015. Major factors affecting severity of obstructive sleep apnea. Indian J Otolaryngol Head Neck Surg 67:114-118.

Lee CH, Jung Hj, Lee WH, Lee Wh, Rhee CS, Rhee Cs ,Yoon I-Y, Yoon Iy, Yun P-Y, Yun Py, Kim J-W, and Kim JW. 2012. The effect of positional dependency on outcomes of treatment with a mandibular. Arch Otolaryngol Head Neck Surg 138:479-483 LID 410.1001/archoto.2012.1452 [doi].

Levendowski DJ, Seagraves S, Popovic D, and Westbrook PR. 2014. Assessment of a neckbased treatment and monitoring device for positional obstructive sleep apnea. J Clin Sleep Med 10:863-871.

Li HY, Cheng WN, Chuang LP, Fang TJ, Hsin LJ, Kang CJ, and Lee LA. 2013. Positional dependency and surgical success of relocation pharyngoplasty among patients with severe obstructive sleep apnea. Otolaryngol Head Neck Surg 149:506-512.

Lindman R, and Stal PS. 2002. Abnormal palatopharyngeal muscle morphology in sleepdisordered breathing. J Neurol Sci 195:11-23.

Lowe AA OT, Ferguson KA, Pae EK, Ryan CF, Fleetham JA. 1996. Cephalometric comparisons of craniofacial and upper airway structure by skeletal subtype and gender in patients withOSA. Am J Orthod Dentofacial Orthop:653-664.

Oksenberg A, Dynia A, Nasser K, and Gadoth N. 2012. Obstructive sleep apnoea in adults: body postures and weight changes interactions. J Sleep Res 21:402-409.

Oksenberg A, Silverberg Ds ,Arons E, Arons E ,Radwan H, and Radwan H. 1997. Positional vs nonpositional obstructive sleep apnea patients: anthropomorphic. chest 112:629-639.

Pevernagie DA, Stanson Aw ,Sheedy PF 2nd, Sheedy Pf 2nd ,Daniels BK, Daniels Bk, Shepard JW, and Shepard JW. 1995. Effects of body position on the upper airway of patients with obstructive sleep. Am J Respir Crit Care Med 152:179-185.

Ravesloot MJ, and de Vries N. 2011. One hundred consecutive patients undergoing drug-induced sleep endoscopy: results and evaluation. Laryngoscope 121:2710-2716.

Saigusa H, Suzuki M, Higurashi N, Higurashi N, Kodera K, and Kodera K. 2009. Threedimensional morphological analyses of positional dependence in patients. Anesthesiology 110:885-890 LID - 810.1097/ALN.1090b1013e31819b31815d31857 [doi].

Sakat MS, Sutbeyaz Y, Yuceler Z, Kantarci M, Kilic K, and Kurt S. 2016. Cephalometric Measurements With Multislice Computed Tomography in Patients With Obstructive Sleep Apnea Syndrome. J Craniofac Surg 27:82-86.

Schwartz RN, Payne RJ, Forest VI, Hier MP, Fanous A, and Vallee-Gravel C. 2015. The relationship between upper airway collapse and the severity of obstructive sleep apnea syndrome: a chart review. J Otolaryngol Head Neck Surg 44:32. 
320

321

322

323

324

325

326

327

328

329

330

331

332

333

334

335

336

337

338

339

340

341

342

343

344

345

346

347

348

349

350

351

352

353

354

355

356

Soga T, Nakata S, Yasuma F, Noda A, Sugiura T, Yatsuya H, Koike Y, Ozaki N, and Nakashima T. 2009. Upper airway morphology in patients with obstructive sleep apnea syndrome: effects of lateral positioning. Auris Nasus Larynx 36:305-309.

Strollo PJ Jr, Soose RJ, Maurer JT, de Vries N, Cornelius J, Froymovich O, Hanson RD, Padhya TA, Steward DL, Gillespie MB, Woodson BT, Van de Heyning PH, Goetting MG, Vanderveken OM, Feldman N, Knaack L, Strohl KP; STAR Trial Group. 2014. UpperAirway Stimulation for Obstructive Sleep Apnea. N Engl J Med. 370:139-149.

Tang XL, Yi HL, Luo HP, Xiong YP, Meng LL, Guan J, Chen B, and Yin SK. 2012. The application of CT to localize the upper airway obstruction plane in patients with OSAHS. Otolaryngol Head Neck Surg 147:1148-1153.

Teerapraipruk B, Chirakalwasan N, Simon R, Hirunwiwatkul P, Jaimchariyatam N, Desudchit T, Charakorn N, and Wanlapakorn C. 2012. Clinical and polysomnographic data of positional sleep apnea and its predictors. Sleep Breath 16:1167-1172.

Torre C, Camacho M, Liu SY, Huon LK, and Capasso R. 2016. Epiglottis collapse in adult obstructive sleep apnea: A systematic review. Laryngoscope 126:515-523 LID 510.1002/lary.25589 [doi].

Tsai WH, Remmers JE, Brant R, Flemons WW, Davies J, and Macarthur C. 2003. A decision rule for diagnostic testing in obstructive sleep apnea. Am J Respir Crit Care Med 167:1427-1432.

Vroegop AV, Vanderveken OM, Boudewyns AN, Scholman J, Saldien V, Wouters K, Braem MJ, Van de Heyning PH, and Hamans E. 2014. Drug-induced sleep endoscopy in sleepdisordered breathing: report on 1,249 cases. Laryngoscope 124:797-802.

Walsh JH, Leigh Ms, Paduch A, Paduch A, Maddison KJ, Maddison Kj, Armstrong JJ, Armstrong Jj, Sampson DD, Sampson Dd, Hillman DR, Hillman Dr, Eastwood PR, and Eastwood PR. 2008. Effect of body posture on pharyngeal shape and size in adults with and without. Sleep 31:1543-1549.

Wang T, Yang Z, Yang F, Zhang M, Zhao J, Chen J, and Li Y. 2014. A three dimensional study of upper airway in adult skeletal Class II patients. PLoS One 9:e95544 LID 95510.91371/journal.pone.0095544 [doi].

Yu XJ, Fujimoto K, Urushibata K. 2003. Cephalometric Analysis in Obese and Nonobese Patients With Obstructive Sleep Apnea Syndrome. chest 124:212-218.

Zohar Y, Sabo R, Strauss M, Strauss M, Schwartz A, Schwartz A , Gal R, Gal R ,Oksenberg A, and Oksenberg A. 1998. Oropharyngeal fatty infiltration in obstructive sleep apnea patients: a. Ann Otol Rhinol Laryngol 107:170-174. 
Figure Legends

361 Figure 1. Flow diagram of the recruitment of study participants

362 PSG test $=$ polysomnography test, $\mathrm{CT}=$ computed tomography

363

364 Figure 2. Diagram showing the anatomical points, lines, and angles used to evaluate craniofacial 365 morphology

$366 \mathrm{~S}=$ sella, $\mathrm{n}=$ nasion, $\mathrm{A}=$ subspinale, $\mathrm{B}=$ supremental, $\mathrm{b}=$ basion, $\mathrm{V}=$ vallecula, $\mathrm{T}=$ tip of tongue,

367 ANS $=$ anterior nasal spine, $\mathrm{PNS}=$ posterior nasal spine.

368

369 Figure 3. Cross-sectional views of the upper airway in the four planes in NPOSA (a,b,c,d) and

$370 \quad \operatorname{POSA}(\mathrm{e}, \mathrm{f}, \mathrm{g}, \mathrm{h})$

371 NPOSA= non-positional obstructive sleep apnea; POSA= positional obstructive sleep apnea; $a, \mathrm{e}=$ cross-

372 sectional views of the palatopharynx; $\mathrm{b}, \mathrm{f}=$ cross-sectional views of the glossopharynx; $\mathrm{c}, \mathrm{g}=$ cross-

373 sectional views of the hypopharynx; $d, h=$ cross-sectional views of the narrowest part of the

374 glossopharynx 
376 Table 1. Comparison of the data associated with anthropometric and cephalometric

377 characteristics and polysomnography (PSG) in positional (POSA) and non-positional (NPOSA)

378 obstructive sleep apnea.

379

380 Table 2. Comparison of the data associated with the cephalometric characteristics in POSA and

381 NPOSA.

382 The English in this document has been checked by at least two professional editors, both native 383 speakers of English. For a certificate, please see:

384 http://www.textcheck.com/certificate/ZVHTfO 


\section{Figure 1 (on next page)}

Flow diagram of the recruitment of study participants

PSG test $=$ polysomnography test, $\mathrm{CT}=$ computed tomography 


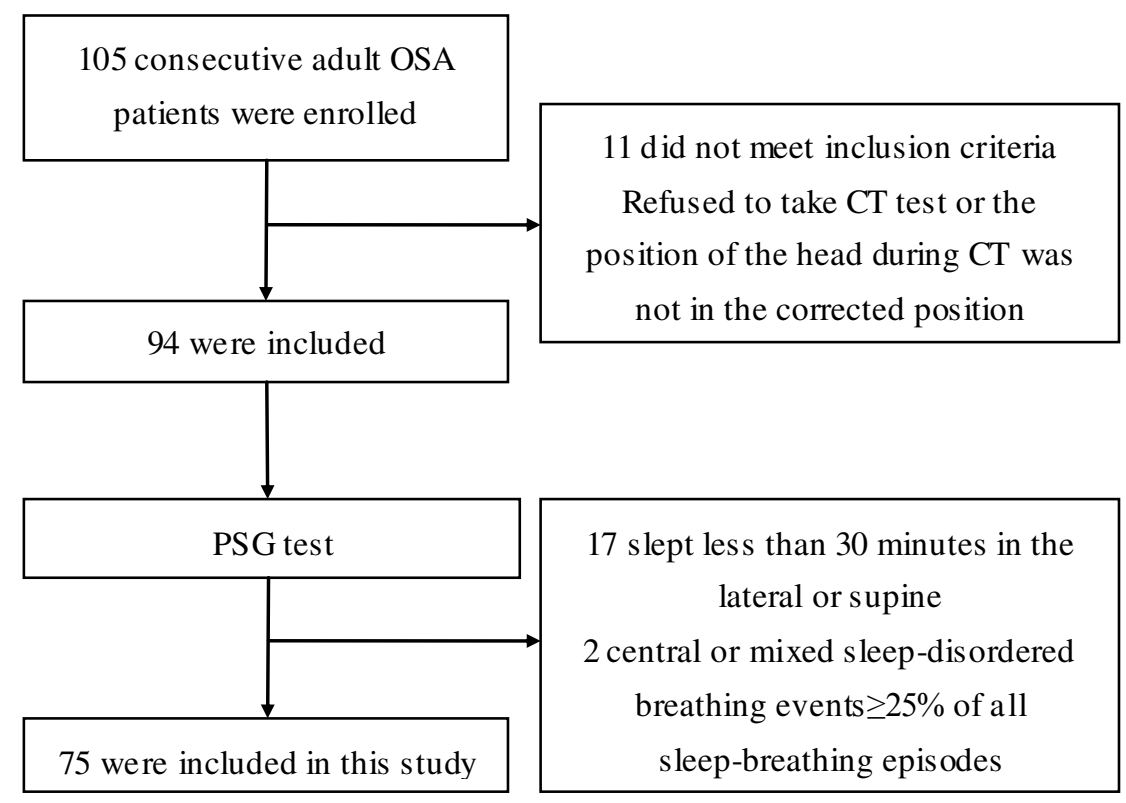


Figure 2

Diagram showing the anatomical points, lines, and angles used to evaluate craniofacial morphology

$\mathrm{s}=$ sella, $\mathrm{n}=$ nasion, $\mathrm{A}=$ subspinale, $\mathrm{B}=$ supremental, $\mathrm{ba}=$ basion, $\mathrm{V}=$ vallecula, $\mathrm{T}=$ tip of tongue, ANS= anterior nasal spine, PNS= posterior nasal spine.

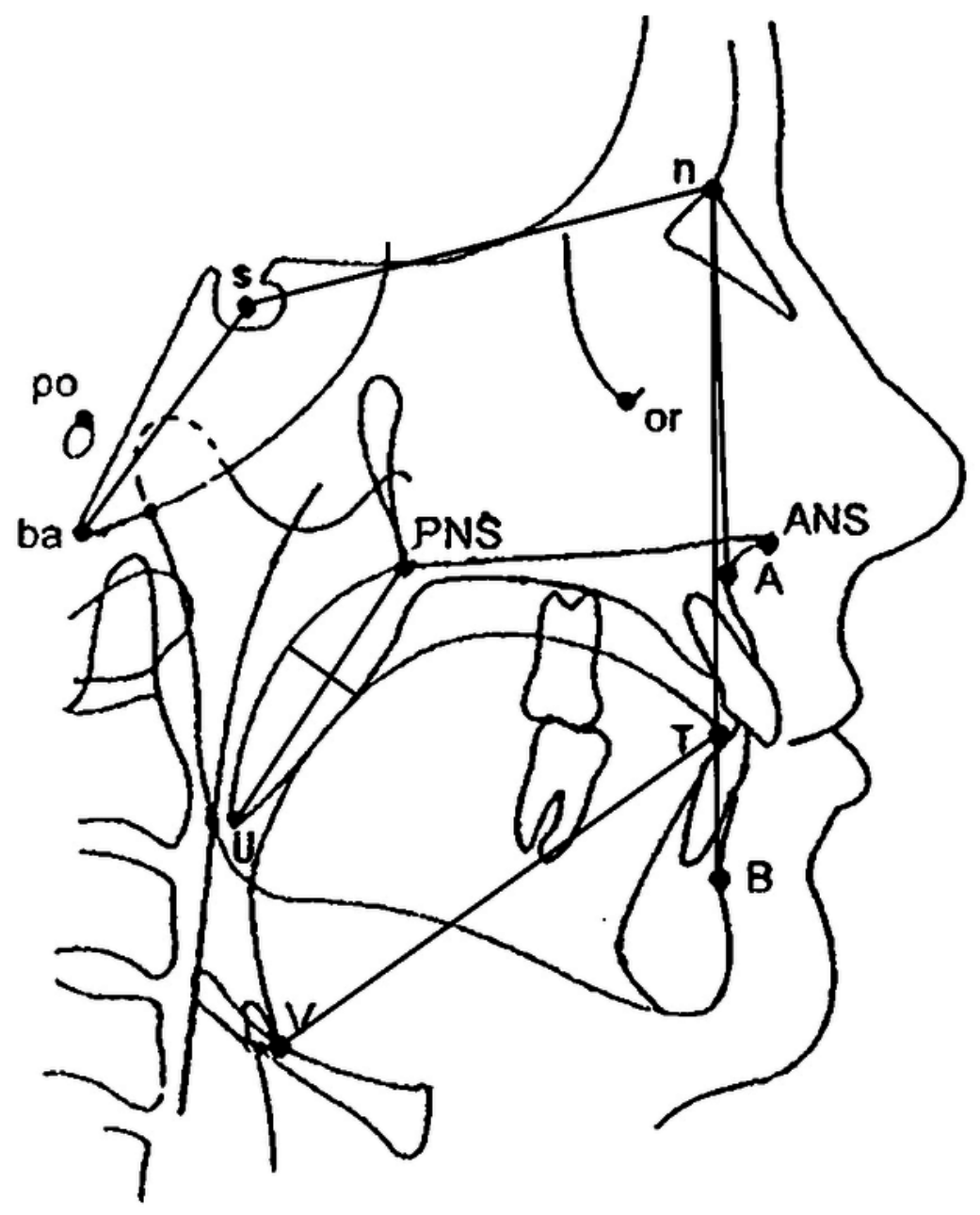




\section{Figure 3}

Cross-sectional views of the upper airway in the four planes in NPOSA $(a, b, c, d)$ and POSA $(e, f, g, h)$

NPOSA = non-positional obstructive sleep apnea; POSA= positional obstructive sleep apnea;

$a, e=$ cross-sectional views of the palatopharynx; $b, f=$ cross-sectional views of the glossopharynx; $c, g=$ cross-sectional views of the hypopharynx; $d, h=$ the cross-sectional views of the narrowest part of the glossopharynx

NPOSA

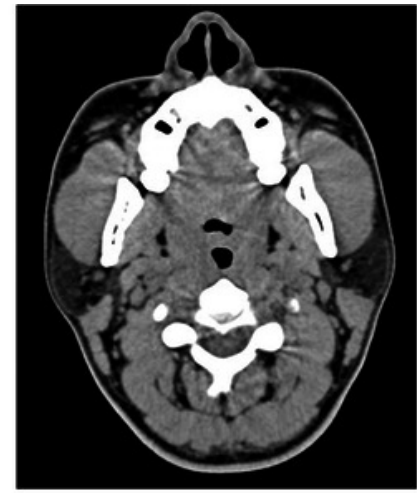

a

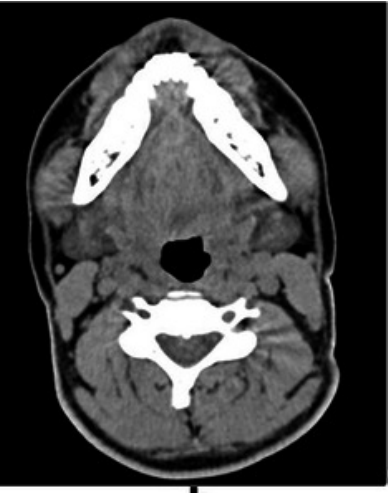

b

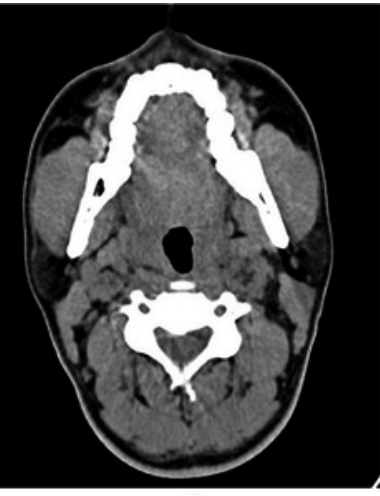

c

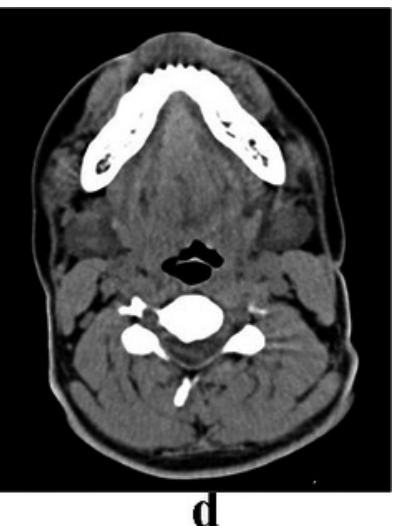

d

POSA

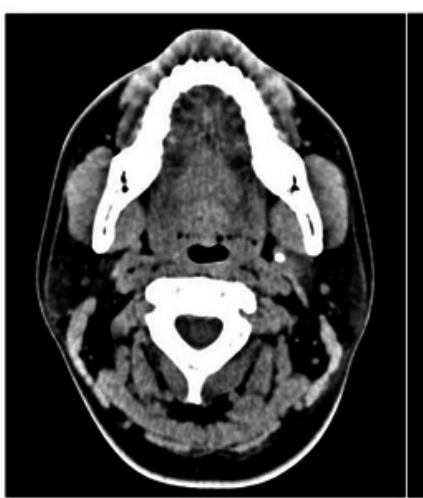

e

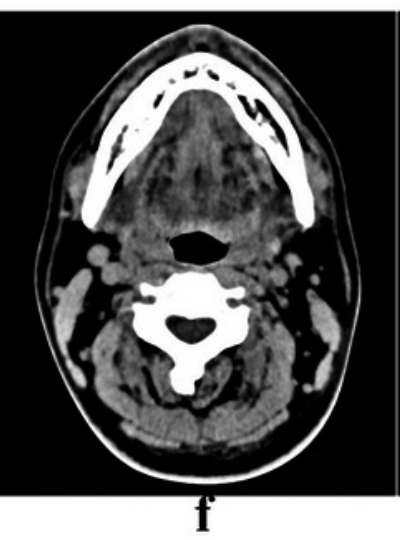

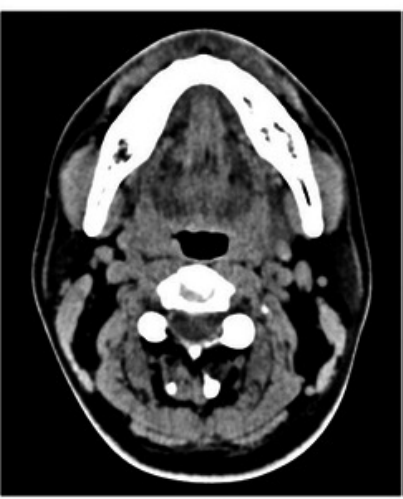

g

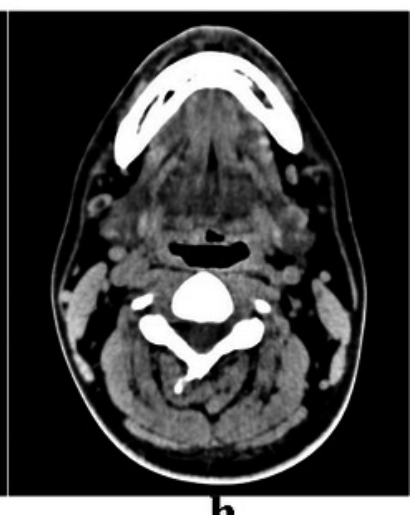

h 


\section{Table $\mathbf{1}$ (on next page)}

Comparison of the data associated with anthropometric and cephalometric characteristics and polysomnography (PSG) in positional (POSA) and non-positional (NPOSA) obstructive sleep apnea.

*: Mann-Whitney test or $t$ test for equal change between groups. $\dagger$ : Test for equal change between groups, adjusted for age ${ }^{\square}$ Normally distributed data are presented as mean \pm standard deviation; non-normally distributed data are presented as median (interquartile range). NPOSA= non-positional obstructive sleep apnea; $P O S A=$ positional obstructive sleep apnea; $\mathrm{BMI}=$ body mass index; $\mathrm{SPL}=$ soft palate length; $\mathrm{SPT}=$ soft palate thickness; $\mathrm{VT}=$ the tongue length; $\mathrm{AHI}=$ apnea hypopnea index; S-AHI= supine-AHI; L-AHI= lateral-AHI. 
1 Table 1. Comparison of the data associated with anthropometric and cephalometric

2 characteristics and polysomnography (PSG) in positional (POSA) and non-positional (NPOSA)

3 obstructive sleep apnea.

\begin{tabular}{lllll}
\hline Indicators & \#NPOSA (45) & \#POSA (30) & $\mathbf{p}^{*}$ & $\mathbf{p}^{\dagger}$ \\
\hline Age (year) & $40.1 \pm 9.0$ & $36.6 \pm 9.6$ & 0.043 & - \\
BMI $\left(\mathrm{kg} / \mathrm{m}^{2}\right)$ & $27.9 \pm 3.1$ & $26.6 \pm 3.1$ & 0.106 & 0.069 \\
SNA $\left(^{\circ}\right)$ & $83.4 \pm 4.2$ & $82.3 \pm 3.8$ & 0.254 & 0.148 \\
SNB $\left(^{\circ}\right)$ & $79.1 \pm 4.5$ & $78.5 \pm 4.6$ & 0.539 & 0.289 \\
ANB $\left(^{\circ}\right)$ & $4.4(2.5)$ & $3.9 \pm 2.7$ & 0.479 & 0.666 \\
BaSN $\left(^{\circ}\right)$ & $139.1 \pm 5.3$ & $140.6 \pm 5.3$ & 0.222 & 0.134 \\
PAS (mm) & $11.3(3.9)$ & $10.8 \pm 3.2$ & 0.449 & 0.288 \\
ANSPNS (mm) & $45.2 \pm 3.8$ & $44.8 \pm 2.9$ & 0.617 & 0.576 \\
SPL (mm) & $36.1 \pm 4.9$ & $33.0 \pm 3.9$ & 0.005 & 0.005 \\
SPT (mm) & $10.2 \pm 2.0$ & $9.6 \pm 1.5$ & 0.159 & 0.219 \\
VT (mm) & $71.2 \pm 5.8$ & $69.1 \pm 4.9$ & 0.106 & 0.094 \\
Total AHI (events/h) & $60.1 \pm 19.4$ & $42.5 \pm 18.5$ & $<0.001$ & $<0.001$ \\
S-AHI & $62.0 \pm 20.3$ & $64.0(20.1)$ & 0.405 & 0.347 \\
L-AHI & $60.1 \pm 23.5$ & $9.5(11.6)$ & $<0.001$ & $<0.001$ \\
\hline
\end{tabular}

4 *: Mann-Whitney test or $\mathrm{t}$ test for equal change between groups.

$5 \uparrow$ : Test for equal change between groups, adjusted for age

$6 \quad$ \# Normally distributed data are presented as mean \pm standard deviation; non-normally distributed data

7 are presented as median (interquartile range). NPOSA= non-positional obstructive sleep apnea; POSA=

8 positional obstructive sleep apnea; $\mathrm{BMI}=$ body mass index; $\mathrm{SPL}=$ soft palate length; $\mathrm{SPT}=$ soft palate

9 thickness; $\mathrm{VT}=$ the tongue length; $\mathrm{AHI}=$ apnea hypopnea index; $\mathrm{S}-\mathrm{AHI}=$ supine-AHI; $\mathrm{L}-\mathrm{AHI}=$ lateral10 AHI. 


\section{Table 2 (on next page)}

Comparison of the data associated with the cephalometric characteristics in POSA and NPOSA.

*: Mann-Whitney test or $\mathrm{t}$ test for equal change between groups. $\dagger$ : Test for equal change between groups, adjusted for age. "Normally distributed data are presented as mean \pm standard deviation; non-normally distributed data are presented as median (interquartile range). NPOSA= non-positional obstructive sleep apnea; POSA= positional obstructive sleep apnea; $\mathrm{SD}=$ sagittal diameter $; \mathrm{CD}=$ coronal diameter $; \mathrm{SD} / \mathrm{CD}=$ sagittal diameter to coronal diameter ratios. 
1 Table 2. Comparison of the data associated with the cephalometric characteristics in POSA and 2 NPOSA.

\begin{tabular}{|c|c|c|c|c|c|}
\hline & Variables & ${ }^{\#}$ NPOSA(45) & ${ }^{\#} \operatorname{POSA}(30)$ & $\mathbf{p}^{*}$ & $p_{\dagger}^{\dagger}$ \\
\hline \multirow{4}{*}{$\begin{array}{l}\text { palatophar } \\
\text { yngeal }\end{array}$} & $\begin{array}{l}\text { cross-sectional } \\
\text { area }\end{array}$ & $67.4(31.1)$ & $80.3(43.0)$ & 0.027 & 0.107 \\
\hline & SD & $8.1(3.5)$ & $8.5 \pm 2.0$ & 0.563 & 0.940 \\
\hline & $\mathrm{CD}$ & $8.8(3.8)$ & $9.7(5.2)$ & 0.040 & 0.124 \\
\hline & $\mathrm{SD} / \mathrm{CD}$ & $0.9(0.6)$ & $0.9 \pm 0.3$ & 0.320 & 0.666 \\
\hline \multirow{4}{*}{$\mathrm{g}$} & $\begin{array}{l}\text { cross-sectional } \\
\text { area }\end{array}$ & $287.4 \pm 86.6$ & $311.5 \pm 94.0$ & 0.257 & 0.363 \\
\hline & SD & $16.3 \pm 3.8$ & $15.9(6.6)$ & 0.888 & 0.955 \\
\hline & $\mathrm{CD}$ & $21.8 \pm 6.4$ & $24.4 \pm 5.5$ & 0.076 & 0.103 \\
\hline & $\mathrm{SD} / \mathrm{CD}$ & $0.7(0.4)$ & $0.6(0.2)$ & 0.261 & 0.242 \\
\hline \multirow{4}{*}{$\mathrm{nx}$} & $\begin{array}{l}\text { cross-sectional } \\
\text { area }\end{array}$ & $123.8(55.6)$ & $153.2 \pm 61.5$ & 0.098 & 0.441 \\
\hline & SD & $10.7(2.5)$ & $10.9 \pm 2.7$ & 0.516 & 0.793 \\
\hline & $\mathrm{CD}$ & $15.7 \pm 5.9$ & $17.2 \pm 5.3$ & 0.276 & 0.218 \\
\hline & $\mathrm{SD} / \mathrm{CD}$ & $0.7(0.5)$ & $0.7 \pm 0.3$ & 0.706 & 0.155 \\
\hline $\begin{array}{l}\text { The } \\
\text { narrowest }\end{array}$ & $\begin{array}{l}\text { cross-sectional } \\
\text { area }\end{array}$ & $189.0 \pm 82.3$ & $211.5 \pm 69.1$ & 0.222 & 0.177 \\
\hline level of & SD & $16.1 \pm 5.1$ & $14.9(6.9)$ & 0.393 & 0.347 \\
\hline glossopha & $\mathrm{CD}$ & $11.5(9.3)$ & $14.5 \pm 6.0$ & 0.055 & 0.029 \\
\hline rynx & $\mathrm{SD} / \mathrm{CD}$ & $1.2(1.6)$ & $1.1(0.9)$ & 0.119 & 0.042 \\
\hline
\end{tabular}

$3 \quad *$ : Mann-Whitney test or $\mathrm{t}$ test for equal change between groups.

$4 \uparrow$ : Test for equal change between groups, adjusted for age.

5 \#Normally distributed data are presented as mean \pm standard deviation; non-normally distributed data are 6 presented as median (interquartile range).

7 NPOSA = non-positional obstructive sleep apnea; $\mathrm{POSA}=$ positional obstructive sleep apnea; $\mathrm{SD}=$ sagittal

8 diameter $; \mathrm{CD}=$ coronal diameter $; \mathrm{SD} / \mathrm{CD}=$ sagittal diameter to coronal diameter ratios. 